NASA/TM-2001-210512

\title{
Fixed-Frequency and Frequency-Agile (Au, HTS) Microstrip Bandstop Filters for L-Band Applications
}

Eileen M. Saenz

Ohio University, Athens, Ohio

Guru Subramanyam

University of Dayton, Dayton, Ohio

Fred W. Van Keuls

Ohio Aerospace Institute, Brook Park, Ohio

Chonglin Chen

University of Houston, Houston, Texas

Félix A. Miranda

Glenn Research Center, Cleveland, Ohio 
The NASA STI Program Office ... in Profile

Since its founding, NASA has been dedicated to the advancement of aeronautics and space science. The NASA Scientific and Technical Information (STI) Program Office plays a key part in helping NASA maintain this important role.

The NASA STI Program Office is operated by Langley Research Center, the Lead Center for NASA's scientific and technical information. The NASA STI Program Office provides access to the NASA STI Database, the largest collection of aeronautical and space science STI in the world. The Program Office is also NASA's institutional mechanism for disseminating the results of its research and development activities. These results are published by NASA in the NASA STI Report Series, which includes the following report types:

- TECHNICAL PUBLICATION. Reports of completed research or a major significant phase of research that present the results of NASA programs and include extensive data or theoretical analysis. Includes compilations of significant scientific and technical data and information deemed to be of continuing reference value. NASA's counterpart of peerreviewed formal professional papers but has less stringent limitations on manuscript length and extent of graphic presentations.

- TECHNICAL MEMORANDUM. Scientific and technical findings that are preliminary or of specialized interest, e.g., quick release reports, working papers, and bibliographies that contain minimal annotation. Does not contain extensive analysis.

- CONTRACTOR REPORT. Scientific and technical findings by NASA-sponsored contractors and grantees.
- CONFERENCE PUBLICATION. Collected papers from scientific and technical conferences, symposia, seminars, or other meetings sponsored or cosponsored by NASA.

- SPECIAl PUBLICATION. Scientific, technical, or historical information from NASA programs, projects, and missions, often concerned with subjects having substantial public interest.

- TECHNICAL TRANSLATION. Englishlanguage translations of foreign scientific and technical material pertinent to NASA's mission.

Specialized services that complement the STI Program Office's diverse offerings include creating custom thesauri, building customized data bases, organizing and publishing research results ... even providing videos.

For more information about the NASA STI Program Office, see the following:

- Access the NASA STI Program Home Page at http://www.sti.nasa.gov

- E-mail your question via the Internet to help@sti.nasa.gov

- Fax your question to the NASA Access Help Desk at 301-621-0134

- Telephone the NASA Access Help Desk at 301-621-0390

- Write to:

NASA Access Help Desk

NASA Center for AeroSpace Information 7121 Standard Drive

Hanover, MD 21076 
NASA/TM-2001-210512

\section{Fixed-Frequency and Frequency-Agile (Au, HTS) Microstrip Bandstop Filters for L-Band Applications}

Eileen M. Saenz

Ohio University, Athens, Ohio

Guru Subramanyam

University of Dayton, Dayton, Ohio

Fred W. Van Keuls

Ohio Aerospace Institute, Brook Park, Ohio

Chonglin Chen

University of Houston, Houston, Texas

Félix A. Miranda

Glenn Research Center, Cleveland, Ohio

Prepared for the

Applied Superconductivity Conference

sponsored by the Institute of Electrical and Electronics Engineers

Virginia Beach, Virginia, September 17-22, 2000

National Aeronautics and

Space Administration

Glenn Research Center 
This report contains preliminary findings, subject to revision as analysis proceeds.

Available from

NASA Center for Aerospace Information 7121 Standard Drive Hanover, MD 21076

Price Code: A02
National Technical Information Service 5285 Port Royal Road Springfield, VA 22100 Price Code: A02 


\title{
Fixed-Frequency and Frequency-Agile (Au, HTS) Microstrip Bandstop Filters for L-Band Applications
}

\author{
Eileen M. Saenz \\ Ohio University \\ Athens, Ohio 45701 \\ Guru Subramanyam \\ Department of Electrical and Computer Engineering \\ University of Dayton \\ Dayton, Ohio 45469 \\ Fred W. Van Keuls \\ Ohio Aerospace Institute \\ Brook Park, Ohio 44142 \\ Chonglin Chen \\ Texas Center for Superconductivity \\ University of Houston \\ Houston, Texas 77204 \\ Félix A. Miranda \\ National Aeronautics and Space Administration \\ Glenn Research Center \\ Cleveland, Ohio 44135
}

\begin{abstract}
In this work, we report on the performance of a highly selective, compact $1.83 \times 2.08 \mathrm{~cm}^{2}\left(\sim 0.72 \times 0.82 \quad \mathrm{in}^{2}\right)$ microstrip line bandstop filter of $\mathrm{YBa}_{2} \mathrm{Cu}_{3} \mathrm{O}_{7-\delta}$ (YBCO) on $\mathrm{LaAlO}_{3}$ (LAO) substrate. The filter is designed for a center frequency of $1.623 \mathrm{GHz}$ for a bandwidth at $3 \mathrm{~dB}$ from reference baseline of less than $5.15 \mathrm{MHz}$, and a bandstop rejection of $30 \mathrm{~dB}$ or better. The design and optimization of the filter was performed using Zeland's IE3D circuit simulator. The optimized design was used to fabricate gold (Au) and High-Temperature Superconductor (HTS) versions of the filter. We have also studied an electronically tunable version of the same filter. Tunability of the bandstop characteristics is achieved by the integration of a thin film conductor (Au or HTS) and the non-linear dielectric ferroelectric $\mathrm{SrTiO}_{3}$ in a conductor/ferroelectric/dielectric modified microstrip configuration. The performance of these filters and comparison with the simulated data will be presented.
\end{abstract}

Index Terms-L-band Bandstop Filter, High Temperature Superconducting (HTS) thin films, $\mathrm{LaAlO}_{3}$ substrates, Ferroelectric thin films, tunable filters.

\section{INTRODUCTION}

Since the discovery of High-Temperature Superconductors (HTS) in 1986, many HTS-based planar microwave components such as resonators and filters have been demonstrated. The use of these HTS films in place of normal conductors (e.g., gold and copper) has reduced conductor losses and consequently insertion loss. In recent years, HTS thin-film based filters have been seriously considered for applications in cellular and PCS communications, as well as for some specific radio- astronomy applications [1]-[4]. For example, HTS pre-select filters are currently being investigated in cellular base-stations for improved selectivity [2].

Also, HTS components have been integrated with ferroelectric thin films to develop low loss, frequency, and phase-agile microwave components [5]-[7]. For radioastronomy applications, the L-band $21-\mathrm{cm}$ hydrogen line $(\sim 1.428 \mathrm{GHz})$ is heavily utilized for deep space exploration. Because the spectrum is crowded at these frequencies, suppression of spurious signals is extremely necessary to avoid degradation of the probing frequency band of interest. Therefore, bandstop filters that offer small size, low loss, and ease of integration into the receiver subsystems while maintaining stringent specifications are highly desirable.

In this paper, we report on the performance of a highly selective, compact $1.83 \times 2.08 \mathrm{~cm}^{2}\left(\sim 0.72 \times 0.82\right.$ in. $\left.^{2}\right)$ bandstop microstrip line L-band filter fabricated using gold $(\mathrm{Au})$ or $\mathrm{YBa}_{2} \mathrm{Cu}_{3} \mathrm{O}_{7-\delta}$ (YBCO) thin films on $\mathrm{LaAlO}_{3}$ (LAO). Two versions of the filter have been studied: a fixed-frequency design and a tunable design using a ( $\mathrm{Au}, \mathrm{YBCO}) / \mathrm{SrTiO}_{3} / \mathrm{LAO}$ superconducting/ferroelectric/dielectric multilayer structure.

\section{DESIGN, FABRICATION, AND TESTING}

The bandstop filter was designed for symmetrical stopband rejection at the center frequency of $1.623 \mathrm{GHz}$, with the stop-band $3 \mathrm{~dB}$ bandwidth (from reference base line) of $5.15 \mathrm{MHz}$ or better. The stop-band rejection needed was $\geq 30 \mathrm{~dB}$ at the center frequency, and the passband insertion 
loss less than $1.0 \mathrm{~dB}$ below $1.614 \mathrm{GHz}$ and above $1.634 \mathrm{GHz}$. To meet the above stringent specifications, the bandstop filter was designed from the traditional Chebychev low-pass prototype synthesis and transformation technique [8]. Due to the higher quality factor (Q) possible with superconductors, the minimum number of poles required was determined to be 3 .

The bandstop filter was implemented using the microstrip edge-coupled resonators coupled to a through line. Desired band-rejection characteristics were obtained by optimizing the spacing between the through line and the resonators, and the length of the coupled sections, with the microstrip lines designed for $50 \Omega$ characteristic impedance on $508 \mu \mathrm{m}(20$ mil) LAO substrates. The final optimization of the filter was performed using Zeland's IE3D electromagnetic simulators [9]. The schematic of the optimized filter is shown in Fig. 1. The performance of the filter as modeled using IE3D is shown in Fig. 2. The modeled data comply with all the aforementioned specifications for this filter.

The $\mathrm{YBCO} / \mathrm{LaAlO}_{3}$ filter considered in this work consisted of a $508 \mu \mathrm{m}$ thick $\mathrm{LaAlO}_{3}$ substrate with an area of $1.83 \times 2.08 \mathrm{~cm}^{2}$ coated with a $600 \mathrm{~nm}$ thick YBCO HTS film. The filter was fabricated using standard photolithography and chemical etching techniques. A gold ( $\mathrm{Au}$ ) version of the filter was also fabricated by depositing a $\mathrm{Au}$ thin film $(\sim 2.5 \mu \mathrm{m}$ thick) on a $\mathrm{LaAlO}_{3}$ substrate using e-beam evaporation. For both versions of the filter a $2.5 \mu \mathrm{m}$ thick gold ground plane film was deposited on the side of the substrate opposite to the circuit.

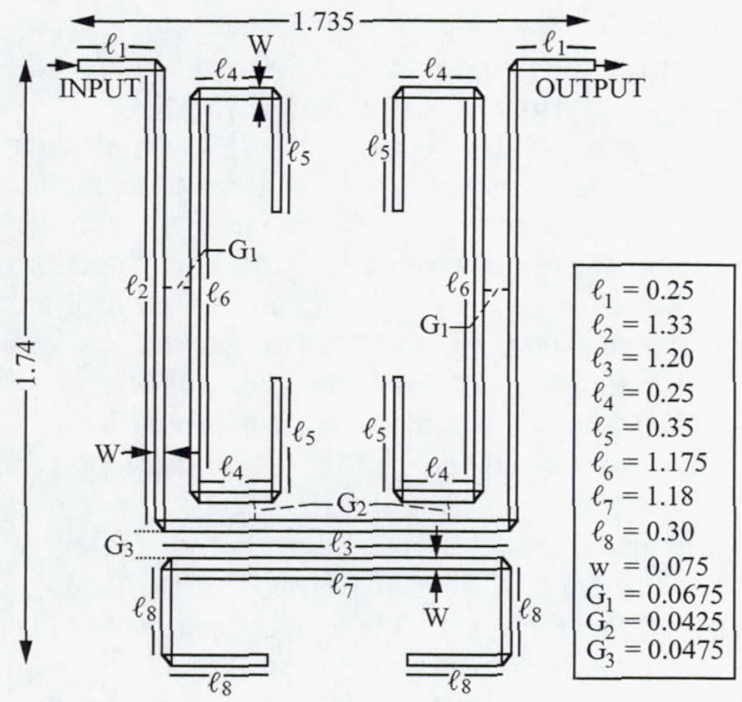

Fig. 1.-Schematic representation of the YBCO/LaAlO 3 bandstop filter. All dimensions are in centimeters.

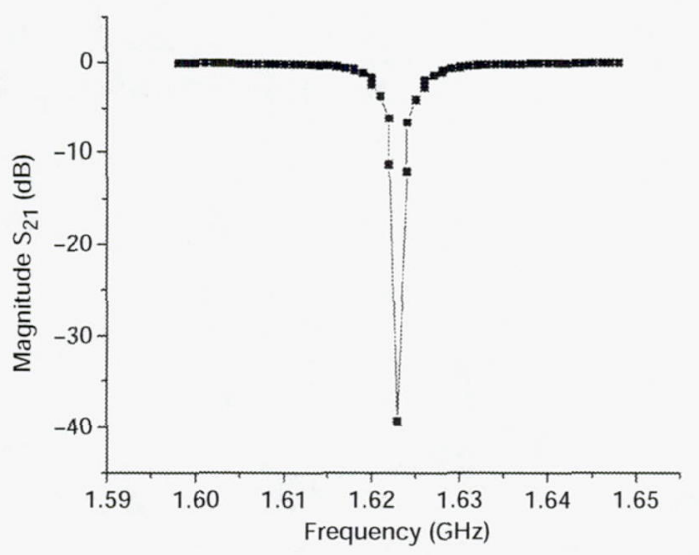

Fig. 2.-Plot of simulated data for the $\mathrm{YBCO} / \mathrm{LAO}$

filter. The filter has a center frequency of $1.623 \mathrm{GHz}$, a bandstop rejection of $39 \mathrm{~dB}$, and a bandwidth of $5 \mathrm{MHz}$ at $3 \mathrm{~dB}$. The simulation was performed using Zeland's IE3D electromagnetic simulator.

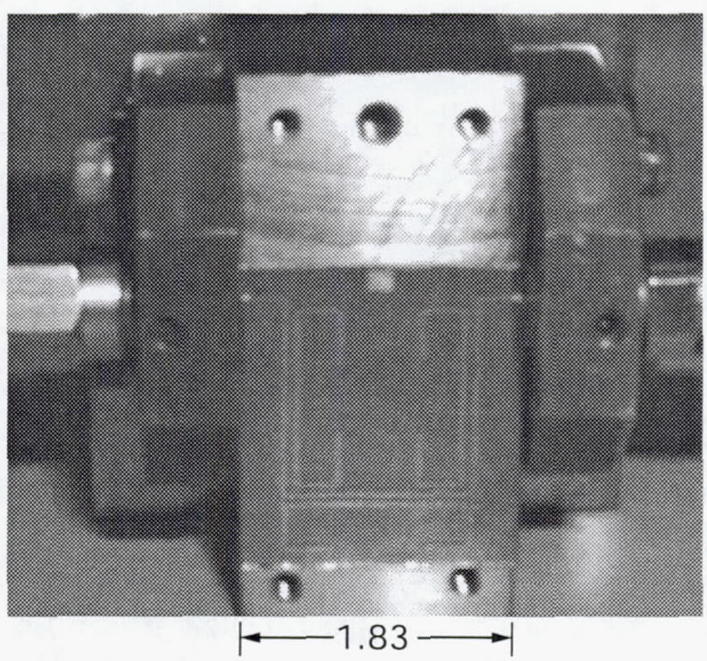

Fig. 3.- The L-band Au/LAO filter mounted on experimental test fixture. The dimension scale is in centimeters.

The microwave characterization of the filter was performed by mounting the filter with silver paint on a custom-made brass test fixture. The microwave signal was launched to the circuit via coaxial SMA connectors. A picture of the filter mounted in the test fixture is shown in Fig. 3. For cryogenic testing of the YBCO filter, the fixture was bolted to the cold finger of a helium gas, closed-cycle refrigerator modified with a vacuum shroud with coaxial feedthroughs for input and output connections to an HP $8510 \mathrm{C}$ network analyzer. Measurements were taken under a vacuum of less than 1 mtorr. 
A tunable version of the filter was also studied. This version was optimized based on the multilayer structure shown in Fig. 4(a), for a ferroelectric thickness of $300 \mathrm{~nm}$, dielectric constant of $\varepsilon_{\mathrm{rSTO}}=1500$ and loss tangent of $\tan \delta=0.01$, which are conservative parameters for STO ferroelectric thin films [10]. Because of the ferroelectric, the optimized design for this version shown in Fig. 4(b) differs from that shown in Fig. 1 for the $\mathrm{YBCO} / \mathrm{LAO}$ filter. The performance of the $\mathrm{YBCO} / \mathrm{STO} / \mathrm{LAO}$ filter obtained using IE3D is shown in Fig. 5. Note that the filter can be tuned by 2 percent to both sides of the center frequency $(1.623 \mathrm{GHz})$ without degrading the specifications outlined earlier in the paper. Beyond these range, although the filter is tunable up to 5 percent with respect to the center frequency, the impedance mismatches introduced particularly for values of $\varepsilon_{\mathrm{rSTO}}>2000$ result in filter performance degradation. For the experimental characterization of this filter, dc voltage was applied through gold wire bonds directly connected to the poles of the filter while keeping the transmission line grounded.

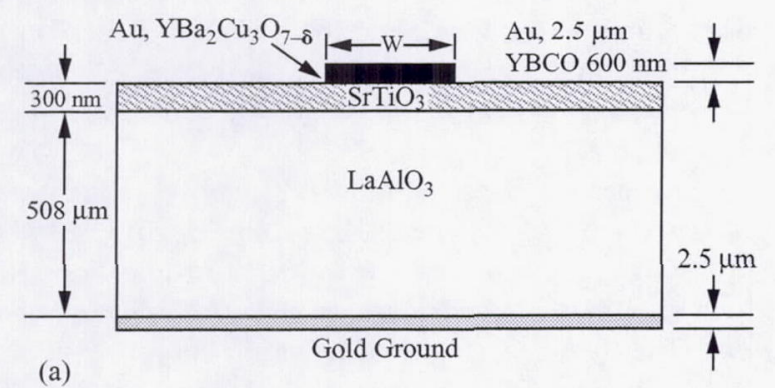

(a)

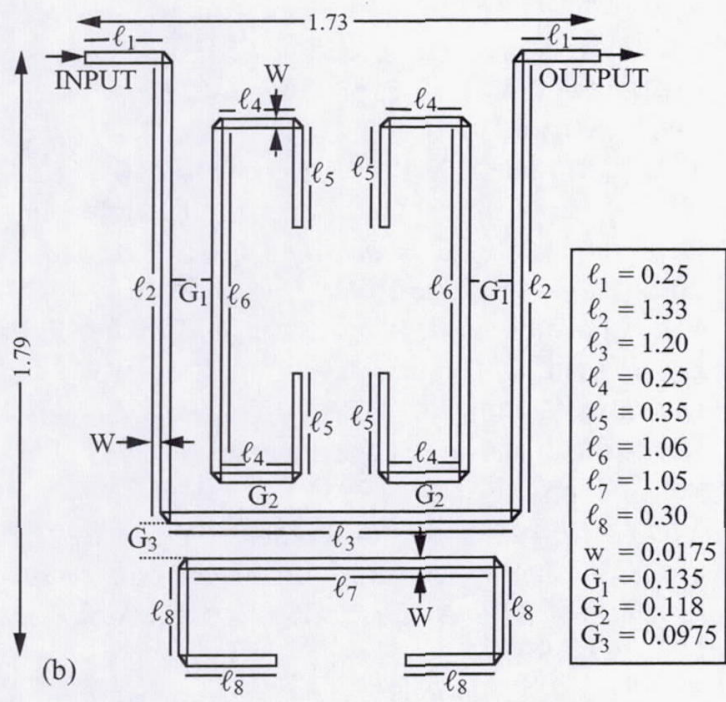

Fig. 4.-(a) Modified microstrip line structure for ferroelectric-base L-band tunable filter. (b) Schematic representation of the $\mathrm{YBCO} / \mathrm{STO} / \mathrm{LAO}$ bandstop filter. All dimensions are in (b) are in centimeters.

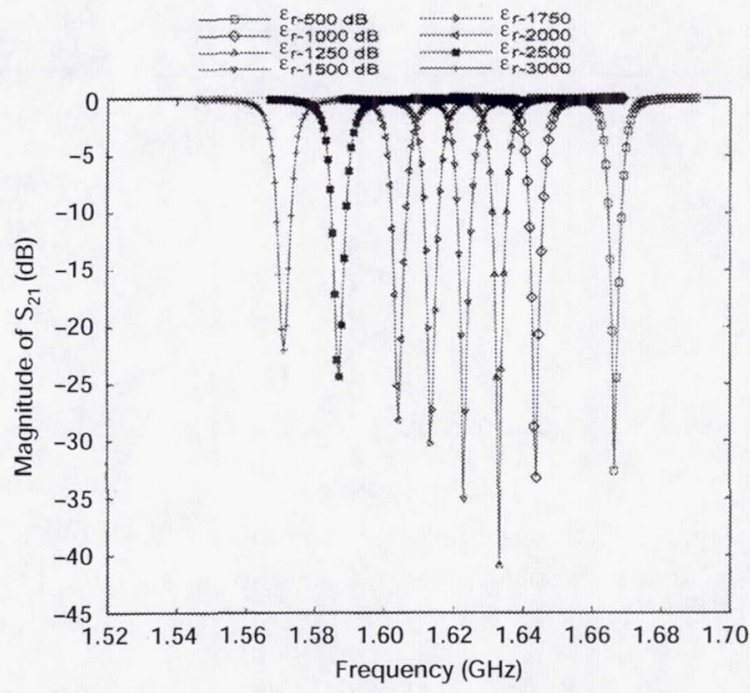

Fig. 5.-Plot of simulated data for the YBCO/ STO/LAO filter for different values of STO's dielectric constant and for $\tan \delta=0.01$.

\section{RESULTS}

The performance of the $\mathrm{Au} / \mathrm{LAO}$ version for the fixedfrequency L-band filter is shown in Fig. 6. The filter exhibits a rejection greater than $32 \mathrm{~dB}$ at $1.625 \mathrm{GHz}$ (only $2 \mathrm{MHz}$ away from specifications) and insertion losses of less than $1 \mathrm{~dB}$ away from the rejection band (markers 2 and 3, Fig. 6). However, the $3 \mathrm{~dB}$ bandwidth of the filter is $\sim 47.5 \mathrm{MHz}$, which is 9 times wider than the specifications. Not withstanding, these are impressive results given the fact that the optimization process was done for a superconducting filter. This filter exhibited a loaded $\mathrm{Q} \sim 650$ at room temperature.

Figure 7 shows the performance of the YBCO/LAO filter. Data were taken at $60 \mathrm{~K}$, which was the temperature at which the filter exhibited the best performance, possibly due to nonoptimal film quality. In this case the filter exhibits a $3 \mathrm{~dB}$ band-width (markers 5 and 4 ) of $\sim 5.5 \mathrm{MHz}$, which is very close to the specified bandwidth. However, it shows a rejection of only $24 \mathrm{~dB}$ at $1.6471 \mathrm{GHz}$ and an insertion loss away from the bandstop frequency worse than those for the Au-filter counterpart, again possibly due to film quality limitations. This filter exhibited a loaded Q 3660. The performance of this filter should be improved by using highquality, double-sided HTS films.

Figure 8(a) shows the performance as a function of temperature of an $\mathrm{Au} / \mathrm{STO} / \mathrm{LAO}$ version of the filter shown in Fig. 4. Note that the reject frequency shifted by $47.5 \mathrm{MHz}$ from 298 to $45 \mathrm{~K}$. Note that the better performance of the filter is realized at $45 \mathrm{~K}$ where the value of $\varepsilon_{\mathrm{r}}$ should be above 1000 . Figure 8 (b) shows the performance of this filter when applying $300 \mathrm{Vdc}$ to the filter's poles $\left(\mathrm{E}_{\max }=0.63 \mathrm{~V} / \mu \mathrm{m}\right)$, which resulted in a frequency shift of nearly 2 percent, consistent with simulations. Although the tunable filter did not live up to all the specifications of the simulated performance shown in Fig. 5 , its performance could be improved by using STO films with higher $\varepsilon_{\mathrm{r}}$ and larger dc bias. 


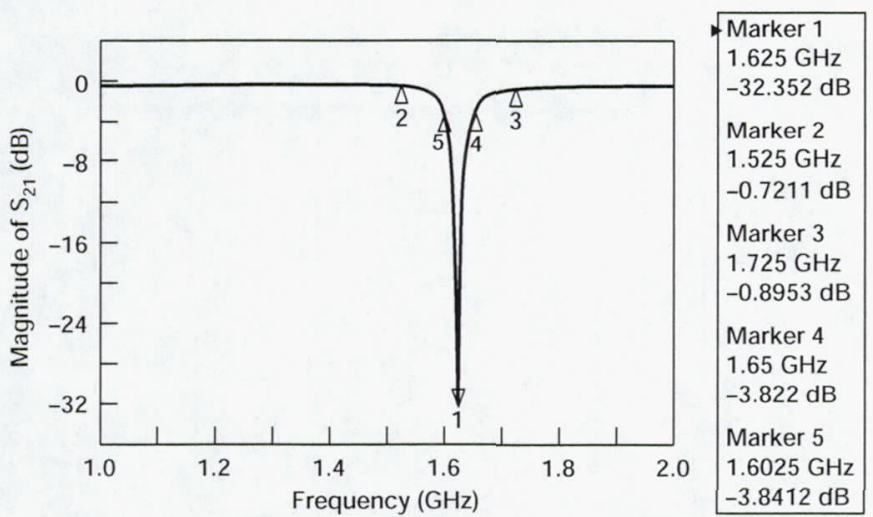

Fig. 6.-Experimental performance of the Au/LAO L-band, 3-pole bandstop filter at room temperature.

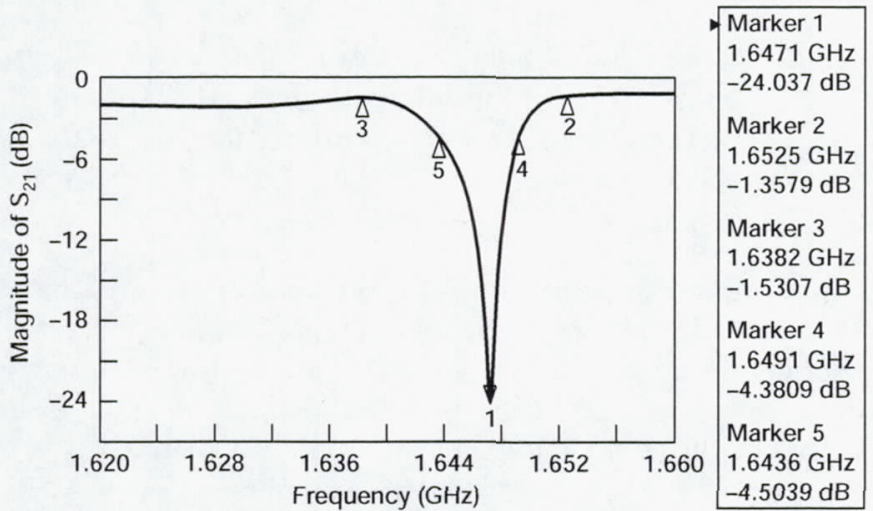

Fig. 7.-Experimental performance of the YBCO/LAO L-band, 3-pole bandstop filter at $60 \mathrm{~K}$.
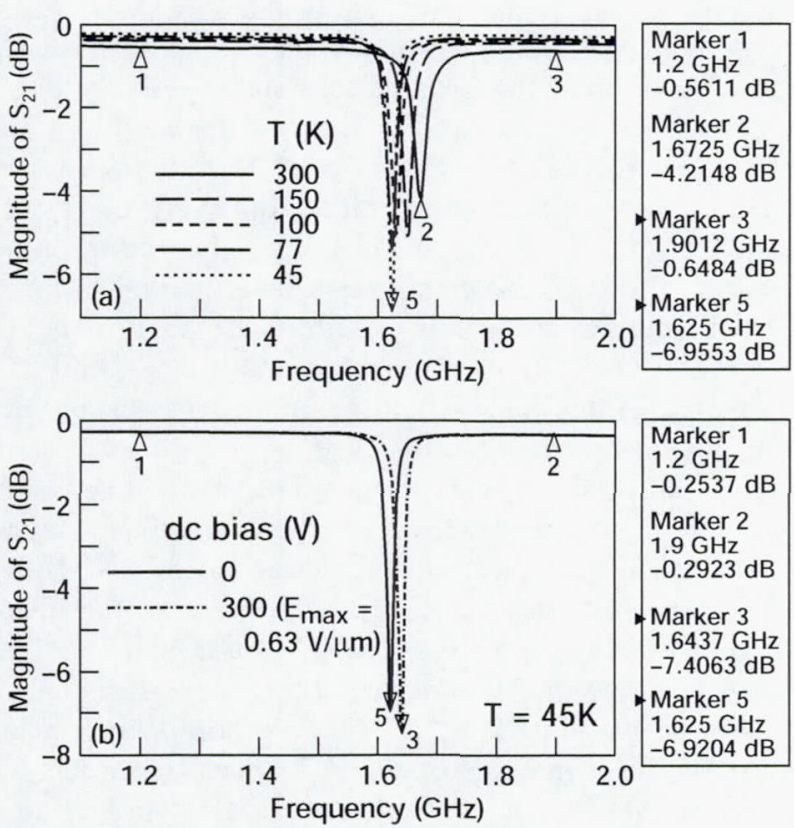

Fig 8.-Experimental performance of an Au/STO/LAO L-Band, 3-pole bandstop filter as a function of temperature (a) and dc bias voltage (b).

\section{CONCLUSIONS}

In this work, a compact, highly selective ( $\mathrm{Au}, \mathrm{YBCO}) / \mathrm{LAO}$ microstrip bandstop filter has been demonstrated for L-band applications. Both the HTS and gold versions of this filter show promising performance to comply with the stringent specifications upon further optimization. The HTS circuit had a $3 \mathrm{~dB}$ band rejection bandwidth of $\sim 5.5 \mathrm{MHz}$, compared to $\sim 47.5 \mathrm{MHz}$ for the gold counterpart, and a rejection of $24 \mathrm{~dB}$, which could be improved using very high-quality, doublesided YBCO thin films. We have also shown the feasibility of a frequency tunable version for this filter. Simulated data for a $\mathrm{YBCO} / \mathrm{STO} / \mathrm{LAO}$ filter predict at least 2 percent tunability while maintaining specifications. Attainment of this level of tunability has been demonstrated with an $\mathrm{Au} / \mathrm{STO} / \mathrm{LAO}$ version of the filter. Experimental work is currently underway for optimization of the $\mathrm{YBCO} / \mathrm{STO} / \mathrm{LAO}$ tunable bandstop filter.

\section{REFERENCES}

[1] J-S. Hong, M.J. Lancaster, R.B. Greed, D. Jedamzik, J.C. Mage, and H.J. Chaloupka, "A High-Temperature Superconducting Duplexer for Cellular Base Station Applications," IEEE Transactions on Microwave Theory and Techniques, Vol. 48, pp. 1336-1343, August 2000.

[2] R. Keenan, "Superconductors Improve Base-Station Sensitivity," Wireless Systems Design, pp. 32-37, July 1997.

[3] R. Simon, "Expanding opportunities for HTS technology in the wireless industry," Superconductor and Cryoelectronics, pp. 9-14, Spring 2000.

[4] M.W. Sinclair, W.E. Wilson, G.G. Moorey, P.B. Sykes, R.J. Bolton, "A cryogenically cooled, thirteen beam, $21 \mathrm{~cm}$ receiver front end," Electrochemical Society Proceedings, Vol. 97-2, pp. 336-346, 1997.

[5] F.A. Miranda, C.H. Mueller, C.D. Cubbage, K.B. Bhasin, R.K. Singh and S. Harkness, "HTS/Ferroelectrics Thin Films for Tunable Microwave Components, IEEE Trans. on Appl. Supercond., Vol. 5, pp. 3191-3194, June 1995.

[6] R.A. Chakalov, Z.G. Ivanov, Yu. A. Boikov, P. Larsson, E. Carlsson, S. Gevorgian, and T. Claeson, "Fabrication and investigation of $\mathrm{YBa}_{2} \mathrm{Cu}_{3} \mathrm{O}_{7-\delta} / \mathrm{Ba}_{0.05} \mathrm{Sr}_{0.95} \mathrm{TiO}_{3}$ thin film structures for voltage tunable devices," Physica $C$, vol. 308, pp. 279-288, 1998.

[7] Yu. A. Boikov and Z.G. Ivanov, "YBa $\mathrm{Cu}_{3} \mathrm{O}_{7-\delta} / \mathrm{SrTiO}_{3}$ epitaxial heterostructures on sapphire substrates," Journal of Alloys and Compounds, Vol. 251, pp. 193-195, 1997.

[8] K. Chang, Handbook of Microwave and Optical Components, Vol. 1, John Wiley, NY, 1989.

[9] Zeland's Software, Inc. 29676, Mission Blvd. Fremont, CA 94539.

[10] M.J. Dalberth, R.E. Stauber, J.C. Price, C.T. Rogers, and D. Galt, "Improved low frequency and microwave dielectric response in strontium titanate thin films grown by pulsed laser ablation," Appl. Phys. Lett., Vol. 72, pp. 507-509 (1998). 
Public reporting burden for this collection of information is estimated to average 1 hour per response, including the time for reviewing instructions, searching existing data sources, gathering and maintaining the data needed, and completing and reviewing the collection of information. Send comments regarding this burden estimate or any other aspect of this collection of information, including suggestions for reducing this burden, to Washington Headquarters Services, Directorate for Information Operations and Reports, 1215 Jefferson Davis Highway, Suite 1204, Arlington, VA 22202-4302, and to the Office of Management and Budget, Paperwork Reduction Project (0704-0188), Washington, DC 20503.

\begin{tabular}{|l|c|c|}
\hline 1. AGENCY USE ONLY (Leave blank) & $\begin{array}{c}\text { 2. REPORT DATE } \\
\text { April } 2001\end{array}$ & $\begin{array}{r}\text { 3. REPORT TYPE AND DATES COVERED } \\
\text { Technical Memorandum }\end{array}$
\end{tabular}

\section{TITLE AND SUBTITLE} 5. FUNDING NUMBERS

Fixed-Frequency and Frequency-Agile (Au, HTS) Microstrip

Bandstop Filters for L-Band Applications

6. AUTHOR(S)

WU-297-60-00-00

Eileen M. Saenz, Guru Subramanyam, Fred W. Van Keuls,

Chonglin Chen, and Félix A. Miranda

7. PERFORMING ORGANIZATION NAME(S) AND ADDRESS(ES)

8. PERFORMING ORGANIZATION REPORT NUMBER

National Aeronautics and Space Administration

John H. Glenn Research Center at Lewis Field

Cleveland, Ohio 44135-3191

E-12464

9. SPONSORING/MONITORING AGENCY NAME(S) AND ADDRESS(ES)

10. SPONSORING/MONITORING AGENCY REPORT NUMBER

National Aeronautics and Space Administration

Washington, DC 20546-0001

NASA TM-2001-210512

\section{SUPPLEMENTARY NOTES}

Prepared for the Applied Superconductivity Conference sponsored by the Institute of Electrical and Electronics Engineers, Virginia Beach, Virginia, September 17-22, 2000. Eileen M. Saenz, Ohio University, Athens, Ohio 45701 (work funded by a NASA/OAI Summer Internship Program for Summer 2000 at NASA Glenn Research Center); Guru Subramanyam, Department of Electrical and Computer Engineering, University of Dayton, Dayton, Ohio 45469-0226 (work funded by a NASA/OAI Summer Faculty Fellowship Program for Summer 2000 at NASA Glenn Research Center); Fred W. Van Keuls, Ohio Aerospace Institute, Brook Park, Ohio 44135; Chonglin Chen, Texas Center for Superconductivity, University of Houston, Houston, Texas 77204; and Félix A. Miranda, NASA Glenn Research Center. Responsible person, Félix A. Miranda, organization code 5640, 216-433-6589.

12a. DISTRIBUTION/AVAILABILITY STATEMENT

12b. DISTRIBUTION CODE

Unclassified - Unlimited

Subject Categories: 33 and 76

Distribution: Nonstandard

Available electronically at http://gltrs.grc.nasa.gov/GLTRS

This publication is available from the NASA Center for AeroSpace Information, 301-621-0390.

13. ABSTRACT (Maximum 200 words)

In this work, we report on the performance of a highly selective, compact $1.83 \times 2.08 \mathrm{~cm}^{2}\left(\sim 0.72 \times 0.82\right.$ in. $\left.{ }^{2}\right)$ microstrip line bandstop filter of $\mathrm{YBa}_{2} \mathrm{Cu}_{3} \mathrm{O}_{7-\delta}$ (YBCO) on $\mathrm{LaAlO}_{3}(\mathrm{LAO})$ substrate. The filter is designed for a center frequency of $1.623 \mathrm{GHz}$ for a bandwidth at $3 \mathrm{~dB}$ from reference baseline of less than $5.15 \mathrm{MHz}$, and a bandstop rejection of $30 \mathrm{~dB}$ or better. The design and optimization of the filter was performed using Zeland's IE3D circuit simulator. The optimized design was used to fabricate gold $(\mathrm{Au})$ and High-Temperature Superconductor (HTS) versions of the filter. We have also studied an electronically tunable version of the same filter. Tunability of the bandstop characteristics is achieved by the integration of a thin film conductor (Au or HTS) and the nonlinear dielectric ferroelectric $\mathrm{SrTiO}_{3}$ in a conductor/ferroelectric/dielectric modified microstrip configuration. The performance of these filters and comparison with the simulated data will be presented.

14. SUBJECT TERMS

L-band bandstop filter; High-temperature superconducting thin films; YBCO HTS films; $\mathrm{LaAlO}_{3}$ substrates; Ferroelectric thin films; $\mathrm{SrTiO}_{3}$; Tunable filters

\begin{tabular}{|c|c|c|}
\hline $\begin{array}{l}\text { 17. SECURITY CLASSIFICATION } \\
\text { OF REPORT }\end{array}$ & $\begin{array}{l}\text { 18. SECURITY CLASSIFICATION } \\
\text { OF THIS PAGE }\end{array}$ & $\begin{array}{l}\text { 19. SECURITY CLASSIFICATION } \\
\text { OF ABSTRACT }\end{array}$ \\
\hline Unclassified & Unclassified & Unclassified \\
\hline
\end{tabular}

